\section{Accuracy of measurements of crown-rump length and biparietal diameter made by inexperienced operators using a real-time scanner}

Ultrasonic measurements of crown-rump length and biparietal diameter in the first two trimesters of pregnancy give an accurate gestational age. ${ }^{12}$ Measurements obtained with real-time scanners and conventional compound B-scanners correlate well, ${ }^{4-5}$ as do measurements obtained by operators with differing experience using a real-time scanner. ${ }^{3}$ I carried out a study to compare measurements made by staff with and without scanning experience.

\section{Apparatus, methods, and results}

A Toshiba linear-array real-time scanner was used. The transducer frequency was $4.5 \mathrm{MHz}$ with 64 elements producing 61 lines of echoes. Adjustable callipers could be moved independently over the screen by a "joystick." There was a built-in freeze-frame.

The operators were 11 residents (inexperienced) and three registrars and one senior registrar (experienced). None of the registrars had had formal training in scanning. To establish the reliability of the experienced operators' measurements the case notes of 134 patients who had been scanned before 30 weeks' gestation were studied after delivery. The cases were consecutive over two separate periods. The actual date of delivery was compared with the date of delivery estimated on the basis of the last menstrual period and the first scan. Eighty-four patients had been sure of their dates: $71(85 \%)$ had delivered within $\downarrow 14$ days of the date estimated from the scan and $60(72 \%)$ within 14 days of the date based on the menstrual period. Fifty patients had been uncertain of their dates : $40(80 \%)$ had delivered within +14 days of the date estimated from the scan. Patients who had had twins, in whom labour had been induced, or who had delivered an infant weighing under $2500 \mathrm{~g}$ were excluded.

The residents were taught how to measure crown-rump length and biparietal diameter by a registrar. After about six weeks they made measurements on their own. Crown-rump length was measured by defining the longitudinal axis of the fetus, moving the callipers to either end, and taking several measurements to ensure that the longest length was obtained. The operator chose the measurements that he considered to be the best. Biparietal diameter was measured by moving the transducer parallel to the falx cerebrum until its echo was obtained in the midline. The callipers were placed on the outer aspect of the anterior parietal bone and the inner aspect of the posterior parietal bone, and an automatic digital readout on the screen gave the measurement. None of the patients was specially prepared for the scan.

Differences in measurements made by residents and registrars. (Figures are numbers of patients)

\begin{tabular}{ccc}
\hline $\begin{array}{c}\text { Difference in } \\
\text { measurements }(\mathrm{mm})\end{array}$ & $\begin{array}{c}\text { Crown-rump } \\
\text { length }\end{array}$ & $\begin{array}{c}\text { Biparietal } \\
\text { diameter }\end{array}$ \\
\hline $0-5$ & 28 & 58 \\
$6-10$ & 7 & 3 \\
$11-15$ & 4 & \\
$>15$ & 2 & \\
\hline
\end{tabular}

Measurements were made at the booking clinic. Patients were not selected. The operator booking the patient was aware of her dates and made the first measurement. Residents were as likely to make the first scan as registrars The second operator, unaware of the patient's dates and the initial scan result, performed a second scan immediately after the first.

Altogether 106 patients were scanned and 108 pairs of measurements made (one patient had twins, and in another both crown-rump length and biparietal diameter were measured). One hundred and two pairs of measurements (41 crown-rump length and 61 biparietal diameter) were available for comparison, measurements in six cases being unsuitable. Crown-rump length measured from 19 to $81 \mathrm{~mm}$ and biparietal diameter from 25 to $93 \mathrm{~mm}$.

Student's paired $t$ test showed no significant difference between the measurements made by the residents and registrars ( $p>0.5$; table). Residents' measurements of crown-rump length tended to be slightly smaller; this was marginally significant $(t=1.96)$ but was not significant when one value was removed $(t=1.65)$. Eighty-five per cent of all the readings, when converted to gestational age, agreed to within eight days.

\section{Comment}

Reliable measurements with a real-time scanner are quick and easy to make. Such scanners will probably become available for routine clinical use in many more obstetric units. These results suggest that clinicians with little scanning experience should be able to obtain reliable estimates of gestational age.

1 Robinson HP, Fleming JEE. A critical evaluation of sonar "crown-rump length" measurements. Br F Obstet Gynaecol 1975;82:702-10.

2 Campbell $S$. The prediction of fetal maturity by ultrasonic measurement of the biparietal diameter. Fournal of Obstetrics and Gynaecology of the British Commonwealth $1969 ; 76$ :603-9.

${ }^{3}$ Docker MF, Settatree RS. Comparison between linear array real-time scanning and conventional compound scanning in the measurement of the fetal biparietal diameter. Br f Obstet Gynaecol 1977;84:924-9.

4 Adam AH, Robinson HP, Fleming JEE, Hall AJ. A comparison of biparietal diameter measurements using a real-time scanner and a conventional scanner equipped with a coded cephalometry system. $\mathrm{Br} \mathcal{F}$ Obstet Gynaecol 1978;85:487-91.

${ }^{5}$ Adam AH, Robinson HP, Dunlop C. A comparison of crown-rump length measurements using a real-time scanner in an antenatal clinic and a conventional B-scanner. Br F Obstet Gynaecol 1979;86 :521-4.

(Accepted 13 March 1981)

Eastern General Hospital, Edinburgh EH6 7LN

I C FULTON, MRCOG, registrar

\section{Anaphylactic reaction to low-molecular-weight porcine factor VIII concentrates}

The management of bleeding in patients with inhibitors to factor VIIIC remains an unsolved clinical problem despite considerable advances in understanding of the molecular biology of factor VIII. Porcine and bovine factor VIII concentrates have been used in the past, especially with severe bleeding problems associated with high antibody levels. ${ }^{1}$ Anaphylactic and allergic reactions and thrombocytopenia, however, have greatly limited their usefulness. ${ }^{2}$

A new highly purified preparation of porcine factor VIIIC, the low-molecular-weight component ${ }^{3}$ has recently become available (Hyate:C, Speywood Laboratories). Mayne $e^{2}$ al $^{4}$ proposed that this product might be valuable in treating patients with haemophilia who had developed antibodies to factor VIIIC. We report a severe anaphylactic reaction after the use of Hyate:C in a non-haemophiliac with an acquired inhibitor to factor VIIIC, which suggests that some caution should be shown in its use.

\section{Case report}

A 71-year-old man suddenly developed spontaneous bruising and a massive ileopsoas haematoma with femoral nerve palsy. This haemostatic defect was due to an acquired inhibitor to factor VIIIC, present at a concentration of $13 \mathrm{U} / \mathrm{ml},{ }^{5}$ resulting in a plasma factor VIIIC concentration of only $0.01 \mathrm{U} / \mathrm{ml}$. Initial treatment with human factor VIII concentrates was unsuccessful. With the inhibitor titre rising to over $50 \mathrm{U} / \mathrm{ml}$ and no evidence of clinical improvement, treatment with porcine Hyate:C was started. He was given $2000 \mathrm{IU}$ Hyate: $\mathrm{C}$ after an intramuscular injection of $10 \mathrm{mg}$ chlorpheniramine maleate. Though there were no immediate ill effects, after 75 minutes he developed a severe anaphylactic reaction, with distinct bronchospasm, widespread pulmonary crepitations, peripheral vasoconstriction, and rapid atrial fibrillation. Immediate administration of adrenaline hydrocortisone, and further chlorpheniramine maleate produced a slow improvement, and over the next 24 hours these symptoms gradually subsided.

Further treatment with porcine concentrates was totally unjustifiable; this was regrettable, particularly in view of the excellent laboratory response obtained with the plasma concentration of factor VIIIC rising to $0.4 \mathrm{U} / \mathrm{ml}$ one hour after the infusion. Furthermore, the platelet count did not fall despite the severity of the reaction and no antibodies to porcine factor VIIIC were detectable after treatment. 